\title{
Creatividad empresarial y autogobierno: un análisis discursivo*
}

\section{Business Creativity and Self-Government: A Discourse Analysis}

Recibido: marzo 4 de 2013 | Revisado: junio 17 de 2013 | Aceptado: septiembre 10 de 2013

\author{
ÁNGela VERA RUIZ** \\ Universidad del Pacifico, Perú
}

Doi: 10.11144/Javeriana.UPSY12-4.ceya

Para citar este artículo: Vera, A. (2013). Creatividad empresarial y autogobierno: un análisis discursivo. Universitas Psychologica, 12(4), 1061-1072. Doi: 10.11144/Javeriana.UPSY12-4.ceya

* Este artículo hace parte de la investigación teórica titulada: "Yo creo": creatividad empresarial y trabajador contemporáneo, presentada como trabajo de grado para optar al título de Magíster en Estudios Culturales de la Universidad de los Andes (2011). Investigación dirigida por la Doctora en Antropología Histórica, Zandra Pedraza Gómez.

** Docente, Departamento de Ciencias Sociales y Políticas, Universidad del Pacífico (Lima, Perú). ResearcherID: M-2815-2013.E-mail: a.veraruiz@ up.edu.pe

\section{RESUMEN}

Este artículo plantea una reflexión sobre las características de un perfil de trabajador creativo que, al estar ligado a la capacidad de autorrealización y autogobierno, se encuentra atravesado por significativas paradojas o tensiones discursivas. Para este fin, se han analizado una serie discursos presentes en manuales sobre desarrollo de creatividad empresarial, centrándose en el nivel textual-representacional del modelo tridimensional del análisis crítico del discurso de Norman Fairclough. La investigación indaga sobre la manera como se legitiman, desde discursos psicológico-organizacionales, formas de ser y estar en el mundo del trabajo, que suponen una experiencia de crecimiento identitario, mientras omiten fines productivos y posibles exclusiones entre las personas.

Palabras claves autores

Creatividad empresarial, autorrealización, autogobierno, subjetividad laboral, análisis crítico del discurso.

Palabras clave descriptores

Psicología social crítica, investigación cualitativa.

\section{A B S T R A C T}

This paper analyses the main features of a creative worker profile that, in order to attain self-actualization and self-government, is crossed by paradoxes or discursive tensions. This investigation is based on the three-dimensional model in Critical Discourse Analysis by Norman Fairclough and particularly on textual-representational analyses level. This research analyses the discourses found in manuals on the development of business creativity in order to figure out how psychological-organizational discourses legitimize the way people behave in the working environment. Business creativity discourses are supposed to bring identity growth while pursuing productive goals and omitting the exclusions among people.

Key words authors

Business creativity, self-actualization, self-government, laboral subjectivity, critical discourse analysis.

Key words plus

Critical Social Psychology, Qualitative Reserch. 


\section{Introducción}

La creatividad, entendida como un proceso mental y social que implica la generación de un producto original, de nuevas ideas o conceptos, o nuevas asociaciones entre ideas y conceptos (Landau, 1987), es una habilidad cada vez más apreciada en los entornos laborales los cuales, en el marco de la actual sociedad del conocimiento, han experimentado grandes transformaciones con respecto a las formas de la fuerza productiva. El paso de los bienes a los servicios y la desmaterialización del trabajo en función del conocimiento, conlleva a que sea la expresión de actividades intelectuales, comunicativas, relacionales y afectivas, lo que actualmente conduzca mayoritariamente a la producción (Bauman, 2006; Bejar, 1993; Deleuze, 1998; Negri, 2004).

En este orden de ideas, la creatividad, entre otros talentos humanos, se codicia como un atributo diferenciador en un mundo laboral inestable y flexibilizado, donde la responsabilidad de supervivencia depende únicamente de la originalidad de sí mismo para reinventarse en el día a día (Bauman, 2006). El valor que se da a la velocidad de respuesta y a "los procesos de creación, intercambio e implicación de los trabajadores en relación con el conocimiento" (Naranjo, 2010, p. 53), hace que cada vez sea más imperativo trabajar en el continuo desarrollo del talento humano.

Reconociendo las actuales condiciones de transformación del campo laboral, el presente artículo se aúna al proyecto de reflexión de la psicología social crítica del trabajo, desde la pregunta por las representaciones discursivas sobre la subjetividad laboral. Se plantea un análisis crítico de los discursos presentes en reconocidos manuales sobre el desarrollo de la creatividad empresarial ${ }^{1}$ los cuales, al adherirse al formato

1 Teniendo en cuenta la gran amplitud de material textual sobre el tema, para la presente investigación la selección del corpus se fundamentó en que se tratase de textos de alta circulación y reconocimiento tanto en ámbitos empresariales como educativos y que, en cuanto a sus contenidos y estilo de escritura, ofrecieran una cierta 'didáctica' (tipo manual) en un lenguaje sencillo orientado a la aplicación práctica de ejercicios sobre desarrollo creativo. Para corroborar estos criterios se consultó en bases de datos y se entrevistó a profesionales y docentes expertos en el campo de la administración de recursos humanos elaborando una lista preliminar de textos, se confirmó la disponibilidad del de la literatura de autoayuda, que brinda consejos y técnicas para enseñar a las personas cómo autogestionar sus talentos (Giddens, 2000), en este caso empresariales, se asumen como "artefactos culturales" capaces de activar nuevas tareas para la subjetividad bajo las demandas del entorno (Pedraza, 2010).

Es importante señalar que los discursos son un conjunto de prácticas lingüísticas que mantienen y promueven las relaciones sociales, la construcción del conocimiento y la configuración de las identidades, y por lo tanto están orientados hacia la acción y tienen consecuencias prácticas en la realidad. (Fairclough, 1992; Potter \& Wetherell, 1998; Stecher, 2010). El modelo teórico y metodológico general en el que se fundamenta este Análisis Crítico del Discurso (ACD) es el de Norman Fairclough (1992, 1995) que reconoce la relación activa, representativa y dialéctica de los discursos con la estructura social.

En cuanto a la metodología, el corpus de la investigación se sistematizó en cuatro categorías analíticas correspondientes a los paradigmas de la investigación psicológica sobre la creatividad: conceptos sobre creatividad, sujeto creativo, proceso creativo y producto creativo (Landau, 1987) y se sometió a un análisis a nivel textual-representacional usando herramientas de análisis lingüístico, para comprender la forma cómo la cohesión, la transitividad, la intertextualidad, la modalidad y el léxico construyen las características estilísticas y discursivas comunes a todos los textos (Fariclough, 1995). El análisis formal posibilitó identificar figuras retóricas (específicamente metáforas y paradojas) en los textos a nivel intra e intertextual ${ }^{2} y$, por medio de la metodología de identificación de repertorios interpretativos (Potter

material del listado en librerías comerciales y bibliotecas de centros educativos especializados, descartando aquellos textos no disponibles y finalmente se consultó el índice de ventas del libro, la cantidad de ediciones, el tipo de publicación y la relevancia del autor con respecto al tema en la región y en el momento en que se hizo el estudio. Con estos criterios se obtuvo un listado definitivo de cuatro libros (véanse, De Bono, Kao, Martin, Schnarch) y un artículo (en la edición especial de la Harvard Business Review sobre creatividad e innovación, véase Amabile), conformando un corpus sólido de textos de altísima circulación y reconocimiento en temas de desarrollo creativo empresarial.

2 Es decir, el análisis textual permitió identificar contradicciones y conflictos así como afinidades conceptuales al interior mismo de cada uno de los textos y de igual manera entre ellos. 
\& Wetherell, 1998), se realizó un análisis semántico centrado en la identificación de las tensiones discursivas que dan cuenta de la construcción de versiones y representaciones acerca del sujeto trabajador creativo y autorrealizado.

En cuanto a los antecedentes sobre este tipo de investigación discursiva en el marco de la psicología social crítica del trabajo, debe señalarse que el ACD como metodología y perspectiva teórica resulta relevante en tanto permite una mirada interdisciplinaria que aborda la complejidad del discurso desde sus múltiples dimensiones, posibilitando la comprensión de los procesos de reestruccturación productiva y flexibilización laboral que han transformando los entornos y las experiencias del trabajo (Stecher, 2010).

La pertinencia que tiene el preguntarse por los discursos psicológico-empresariales sobre el desarrollo de la creatividad y su relación con la configuración de subjetividades laborales acordes con las demandas neoliberales, se evidencia al corroborar en diferentes abordajes del campo de las ciencias sociales y la psicología crítica, una creciente preocupación por las nuevas exigencias que tienen las personas en el mundo del trabajo y los altos costos que ello conlleva a nivel de la subjetividad. Este trabajo se soporta y enriquece en la aproximación a autores que han trabajado el tema de la configuración de subjetividades y las particularidades del ámbito del trabajo en el marco de la contemporaneidad (Bauman, 2005, 2006, 2007; Bejar, 1993, 2007; Giddens, 1996, 2000; Negri, 2004; Pulido, 2004, 2007; Rose, 1998, 1999; Sennett, 2000; Stecher, 2010; Wakerdine, 2006).

Lejos de querer llegar a conclusiones definitivas con respecto a la situación compleja de constitución de la subjetividad laboral en el marco del autodesarrollo de competencias como la creatividad, este artículo busca ante todo hacer un aporte a los estudios de la psicología social crítica del trabajo, entendiendo que desde el análisis discursivo también se puede develar la manera en que las dinámicas psicológicoorganizacionales imperantes, representan nuevas configuraciones y demandas para los sujetos trabajadores contemporáneos. La experiencia del sí mismo como cierto tipo de persona (criaturas de libertad, de faculdades personales, de autorrealización) es el resultado de una variedad de tecnologías que toman los modos de ser humano como objeto (Rose, 1998).

\section{Creatividad, autorrealización y tensión}

El mundo está lleno de opuestos. Por supuesto, cualquier atributo, concepto o idea carece de significado sin su opuesto. Lao-tzu escribió Too-te Ching en donde recalca la necesidad para un líder exitoso de mirar los opuestos a su alrededor. Todo comportamiento consiste en opuestos. Aprenda a ver las cosas hacia atrás, de adentro hacia afuera, de arriba hacia abajo. (Schnarch, 2008, p. 111)

La anterior cita, extraída de un manual de creatividad empresarial, plantea un tema que resulta de interés analizar: el de lidiar con la coexistencia de opuestos, o lo que podría también denominarse paradojas o tensiones, como requisito fundamental para ser creativo y exitoso.

Esta noción se soporta también en algunas teorías canónicas del campo psicológico con respecto al tema de la creatividad y la autorrealización como la de Abraham Maslow (2001) quien, tras años de analizar las características de personas exitosas en el campo personal y profesional a quienes denominó como "verdaderamente humanas" por poseer un alto nivel de autoconciencia y bienestar psíquico, llegó a la conclusión de que la autorrealización solo era posible gracias a altos niveles de creatividad que configuraban una forma particular de ser.

Tras analizar los estados mentales propios del acto creativo, Maslow (2001) definió la creatividad como un proceso de inherente tensión y búsqueda de equilibrio, en el que coexisten estados mentales mutuamente excluyentes como serían, por un lado, la despersonalización y, por otro, la integración consigo mismo y con el mundo. En consonancia, otras perspectivas psicológicas (dentro del cognitivismo y la psicodinámica) también explican que el ser y acontecer creativo depende de lograr resolver una situación paradójica en la que, la coexistencia de dos estados, situaciones o pensamientos opuestos, permite dar lugar a algo original que va más allá de una síntesis (Gardner, 1995a, 1995b; Winnicott, 2008). 
Si bien estos postulados son producto del rigor investigativo en distintas áreas psicológicas, vale señalar que ellos sostienen representaciones legitimadas sobre un sujeto creativo y autorrealizado que estima de manera positiva la tensión y es capaz de lidiar con ella para producir algo más. Estas representaciones tendrían especial eco en el actual campo laboral, entendido como un nuevo escenario privilegiado para la expresión del yo y el desarrollo de las propias capacidades (Bejar, 1993), cuyas características de flexibilización, inestabilidad, proclividad al cambio y a la volatilización del capital, privilegiarían la noción de aprovechar creativamente los escenarios inciertos y contradictorios (Bauman, 2006).

El género del manual de desarrollo creativo, analizado en esta investigación, tiene un alto componente intertextual, es decir, versa sobre una pluralidad de géneros, narrativas y conceptos de diferentes áreas del conocimiento, entre los que establece una interrelación semántica (Fairclough, 1995). $\mathrm{Al}$ adoptar representaciones psicológicas del sujeto creativo y combinarlas con dosis de pedagogía, administración y economía, ofrece un hibrido discursivo de fácil lectura y aplicación que celebra la noción del ser creativo como alguien que aprovecha, incluso disfruta, la contradicción:

Los líderes a quienes he estudiado tienen en común por lo menos una característica, aparte de su talento para la inno $\neg$ vación y el éxito a largo plazo. Tienen la predisposición y la capacidad de considerar dos ideas diametralmente opues $\neg$ tas al mismo tiempo. Entonces, sin perder la calma y decidirse sencillamente por una de las dos alternativas, pueden producir una síntesis superior a cualquiera de las dos ideas iniciales. Pensamiento integrador es la expresión que he uti $\neg$ lizado para designar este proceso, o más exactamente esta disciplina de reflexión y síntesis que distingue a las empresas excepcionales y a quienes las dirigen. (Martin, 2008, p. 6)

En efecto, aquí se plantea una particular forma de ser sujeto creador y exitoso, que está explícitamente sostenida en la coexistencia de estados contradictorios que vale la pena estudiar. Para analizar las representaciones que ofrecen los manuales con respecto a la experiencia creativa en tensión, se rastreó el uso retórico de paradojas. La paradoja es una figura de pensamiento que emplea expresiones o enunciados que envuelven de manera explícita o implícita una contradicción. En el siguiente aparte se analizará una de las tensiones encontradas en los textos.

Resulta de interés señalar que los manuales sobre creatividad empresarial garantizan que es posible llegar a ser creativo por medio del seguimiento de pautas e instrucciones precisas y que, por lo tanto, la creatividad no es un talento excepcional sino un proceso que puede ser entrenado y aplicado a los más diversos ámbitos de la vida humana y, que en caso de desarrollarlo, conllevaría a "distinguirse como excepcional" (Martin, 2008), ser un "líder exitoso" (Schnarch, 2008) o ser "verdaderamente humano" (Maslow, 2001).

La creatividad sería entonces condición y a la vez efecto del éxito, en este caso, en el ámbito laboral. Esto lleva a preguntarse por cuáles serían las condiciones que posibilitan referirse a personas "verdaderamente humanas", mientras que implícitamente dejan un espacio residual, difícilmente representable, para aquellas que, se supone, no lo son. Bejar (1993) señala que en el ámbito del trabajo existe cierta concepción psicologista que invita a tener una personalidad desenvuelta y 'exitosa' mientras denigra posiciones subjetivas que se apartan de este ideal.

La tensión entre opuestos, se presenta como una condición necesaria para pensar al sujeto creativo. Esto no solo porque el acto creativo por excelencia dependa de la coexistencia de estados físicos o mentales contradictorios (Winnicott, 2008), sino, ante todo, porque necesariamente al referirse a sujetos creativos surge allí su polo opuesto: aquellos sujetos que no lo son. Hablar de una persona verdaderamente creativa y por tanto autorrealizada, siempre implicará una contraparte: un 'otro' que no encaja en el ideal de subjetividad representado en los discursos sobre el desarrollo humano.

Analizar la figura retórica de la paradoja en los manuales de creatividad, permite abordar de manera comprensiva las representaciones contradic- 
torias que allí circulan acerca del sujeto trabajador creativo y autorrealizado. Dichas representaciones se asumen en esta investigación como "tensiones discursivas" en las que dos nociones contradictorias dentro del mismo texto se presentan como afines de manera naturalizada, planteando una paradoja identitaria:

Naturalmente, hay muchos otros estudiosos del tema [de la creatividad] y encontramos conceptos [sobre la personalidad creativa] que incluso pueden parecer contradictorios, tales como: enérgicos y tranquilos, inteligentes e ingenuos, disciplinados e irresponsables, imaginativos y realistas, extrovertidos e introvertidos, orgullosos y humildes, rebeldes y conservadores, sufridos y triunfadores... (Schnarch, 2008, p. 10)

Es de interés preguntarse por las implicaciones que puede tener el hablar de una "personalidad creativa" marcada por la coexistencia de contradicciones, a nivel de la configuración de procesos cognitivos, emocionales y relacionales de los trabajadores, máxime si la resolución de la tensión radica en el 'ser' capaz de ejercer su creatividad versus el 'no ser' creativo:

La inteligencia, observó F. Scoth Fitzgerald es la capacidad de tener en la cabeza dos ideas contradictorias al mismo tiempo. La creatividad ciertamente puede realizar esa proeza: Contradicción y divergencia crean confusión, tensión, inquietud. Y el anhelo casi instintivo de vencer o sobreponerse a la contradicción solo se puede realizar con creatividad. (Kao, 1997, p. 7)

Abordar la problemática de la subjetividad, o de las versiones del ser persona (Rose, 1998), en relación con el análisis de los discursos sobre la creatividad empresarial, contribuye a la comprensión de las nuevas demandas que configuran un tipo de sujeto trabajador capaz de responder a condiciones laborales que incluso podrían ser adversas. Bajo el título de "trabajo creativo" se promueve una continuidad entre la actividad laboral y la vida personal, lo que conlleva a una identificación entre trabajo y trabajador que se afiliaría 'naturalmente' con la noción de éxito, un "autodesafío" en el que se prueba la personalidad (Bejar, 1993).

Rose (1997) explica que los sujetos contemporáneos se definen entonces como "sujetos de gobierno", es decir, como individuos activos que buscan "realizarse a sí mismos" y maximizar su calidad de vida mediante actos de elección que les confieren sentido y valor. Se trata de personas definidas en su esencia como criaturas libres, autónomas y "autogobernadas", que cumplen sus obligaciones ciudadanas conforme consiguen su propia realización, siendo responsables respecto a su propio destino. El "autogobierno" se configura como una forma de poder que se ejerce sobre la vida cotidiana y que ordena y designa a los individuos por una ley de verdad sobre sí mismos que debe ser reconocida. Los individuos se transforman en sujetos amarrados a su propia identidad por la conciencia o el conocimiento de sí mismos (Foucault, 1998) y su capacidad de autogestión. Como se analizará en los resultados, esta noción cobra especial fuerza en la búsqueda del desarrollo creativo empresarial.

\section{Resultados}

Para el análisis de las paradojas o tensiones discursivas encontradas en los manuales de creatividad empresarial, se recurrió a la identificación de repertorios interpretativos, que consiste en la lectura e interpretación de los patrones estilísticos comunes a todos los textos, para evidenciar la naturalización de ciertos conceptos, comportamientos y prácticas (Potter \& Wetherell, 1998).

Los repertorios son elementos discursivos que componen versiones de las acciones, los procesos cognitivos y otros fenómenos mentales y sociales y derivan de la presencia de una o más metáforas o figuras retóricas claves en el discurso (Potter \& Wetherell, 1998). Para los resultados del presente artículo, se expone un repertorio interpretativo que explica la tensión entre sujetos creativos y no creativos, exponiendo un perfil profesional que estaría afiliado al liderazgo y autogobierno. El repertorio interpretativo se construye y desarrolla recurriendo 
a las citas textuales de los manuales para, a partir de ellas, proponer un nuevo texto analítico.

\section{La tensión discursiva entre el líder visionario y el empleado conformista}

La problemática central que plantea esta tensión discursiva, en la que se buscará explicar la manera cómo se define en los textos el perfil profesional del sujeto trabajador creativo, queda claramente expuesta y metaforizada en el siguiente fragmento proveniente de las palabras de un reconocido empresario citado en un manual de creatividad:

En una colmena hay diferentes tipos de abejas: obreras y exploradoras (...). Las abejas exploradoras son las abejas creativas de la colonia. Vuelan continuamente para encontrar nuevas fuentes de polen. Cuando encuentran una, vuelan de regreso a la colmena e indican a sus compañeras dónde se encuentra el nuevo descubrimiento. Entonces van las abejas obreras, de una manera muy bien ordenada y controlada y traen el polen. Pero las abejas exploradoras no recogen ni una gota de néctar ni un grano de polen; ellas están hechas solo para volar por ahí y explorar. Ese es el equilibrio que me gustaría crear en una empresa (...). (Jan Carlzon, exdirector ejecutivo de SAS, citado por Goleman, Kaufman \& Ray, 2009, p. 158)

En efecto, esta metáfora del entorno laboral como una colmena donde se distinguen creativos de no creativos, obreros de exploradores, evidencia una brecha entre los trabajadores y sus funciones. Entre recolectar juiciosa y ordenadamente el polen y revolotear buscando nuevas fuentes, se separa a los creativos de los que no lo son y se señala "una tensión natural entre los que podríamos llamar tipos corporativos de ley y orden y gente creativa" (Carlzon, citado por Goleman et al., 2009, p. 157).

Entonces, "Exige la creatividad un grupo particular, uno que se caracterice por un nivel determinado de destreza?" (Kao, 1997, p. 35). La promesa retórica de estos manuales es que las personas de todo tipo deberían poder tener acceso al desarro- llo de su creatividad. En la introducción al libro El espíritu creativo Daniel Goleman (2009) señala:

Si procuras encontrar el espíritu creativo en algún sitio exterior a ti, estás buscando en el lugar errado. En el título de este libro, "espíritu" significa el hálito de la vida, y el obrero sueco revela su espíritu en la pieza de acero a la que le da forma y pule. Y el espíritu creativo está dentro de ti cualquiera que sea tu ocupación. La clave por supuesto radica en liberarlo. Esperamos que este libro te ayude a lograrlo. (p. 14)

Si bien esta promesa se presenta de manera reiterada en todos los manuales, su análisis arroja una contradicción discursiva en la que, mientras se promueve de manera explícita una noción democratizadora de la creatividad, por otra parte se reconoce que no necesariamente todos pueden ser "abejas exploradoras" pues, como señala De Bono (1994) aunque "la destreza creativa general deberían adquirirla todas las personas integrantes de cualquier organización, sin excepción alguna, esto no significa que en todos los niveles se requiera el mismo grado de creatividad" (p. 384). Se trata de una creatividad que debe ser entrenada de acuerdo al perfil de cargo y a las diferencias profesionales y personales existentes entre los trabajadores pues "la creatividad no es ni una herramienta ni una habilidad más; es quizá la única forma de ser empresarios (o ejecutivos o gerentes)" (Schnarch, 2008, p. 82).

De hecho, implícitamente los manuales se dirigen a un segmento de la población trabajadora cuyas labores administrativas e intelectuales se concentran en cargos ejecutivos y gerenciales. De Bono (1994) explica que "es preciso poner los hábitos y las técnicas del pensamiento lateral al alcance de todas las personas que actúan a nivel gerencial" ( $\mathrm{p}$. 384). La idea inicial de una creatividad para "todos" se desplaza y concentra de manera específica en el personal que ocupa cargos directivos o que cuenta con la formación para llegar a ocuparlos, quizás por ello se sugiere que "todos los estudiantes universitarios y todos los ejecutivos deberían leer este libro" (De Bono, 1994, p. 425). 
El análisis devela que mientras se plantea la necesidad de conseguir un tipo de profesional apto para el trabajo creativo que vaya "dejando atrás la preocupación por lo físico y lo financiero para atender a lo puramente humano: imaginación, inspiración, ingenio e iniciativa" (Kao, 1997, p. 4), y que sean "personas creativas y emprendedoras, pero no solo para establecer empresas, sino para innovar en las formadas, haciéndolas más productivas y competitivas para los nuevos escenarios políticos y económicos" (Schnarch, 2008, p. 89), a la vez se denigra de los trabajadores que no ejercen su creatividad. Se trataría de un grupo de personas "holgazanas", “débiles de corazón” y conformistas (Kao, 1997): "Como apunta un proverbio chino, solo los peces veloces y dinámicos remontan la corriente; los troncos inertes flotan río abajo" (Schnarch, 2007, p. 89).

Aquí se plantean diferencias jerárquicas y constitutivas del yo entre lo que Bejar (1993) denomina el trabajo rutinario, ajeno, instrumental y que no ofrece compensaciones fuera de las puramente económicas, y el trabajo creativo, apropiado a la formación y capacidad personal que se asocia con el éxito. El primero se asume como una labor frustrante y el segundo se idealiza y desea como oportunidad constitutiva en el desarrollo mismo de la personalidad. Dado que es a nivel gerencial donde se busca ante todo el despliegue creativo, la figura del líder promotor de la creatividad se vuelve fundamental en los textos analizados:

La mayoría del trabajo creativo que se lleva a cabo hoy en día en el mundo empresarial lo hacen personas cuyos nombres nunca figurarán en los anales de la historia (...) trabajan en organizaciones cuyos directores conscientemente crean un ambiente que respalda estas características. (Amabile, 2000, p. 30)

No es conveniente que el asunto de la creatividad se movilice libremente entre las cabezas subalternas, pues siempre "es necesario que dentro de una empresa alguien sea "responsable" del esfuerzo creativo. ¿Quién debe serlo? Mucho depende de la persona que dirige la puesta en marcha de las actividades" (De Bono, 1994, p. 334). "Es bastante más importante que sea quien fuere el responsable de marcar las metas, las deje bien claras en la organización y que esas metas permanezcan estables durante un periodo de tiempo significativo" (Amabile, 2000, p. 11).

La meta de la creatividad partirá entonces desde los altos ejecutivos, quienes servirán "como modelos dignos de ser imitados, perseverando cuando surjan problemas graves y fomentando la colaboración y comunicación dentro del equipo (...) [con] actitudes y comportamientos que fomentan y nutren la creatividad" (Amabile, 2000, p. 18). Son los líderes quienes deberán ser entrenados en la responsabilidad del ejercicio de la creatividad, reconociendo la tensión existente con su contraparte: un grupo de individuos con poca iniciativa que están lejos de ser creativos y que se caracterizan por tener un pensamiento convencional que "oculta las posibles soluciones en lugares donde es imposible encontrarlas y fomenta la ilusión de que no es posible llegar a una solución imaginativa (...) refuerza una y otra vez la manida lección de que en la vida siempre hay que aceptar sacrificios desagradables y poco atrayentes" (Martin, 2008, p. 50).

El líder, promotor de la creatividad, sería una suerte de figura mesiánica capaz de resolver las carencias creativas de sus subalternos y promover el desarrollo organizacional apelando a estrategias emotivas más allá de las pautas de administración convencionales. Se trataría ya no de una figura autoritaria sino de un "facilitador" que no justifica sus órdenes, de hecho ni siquiera las da de manera explícita, sino que posibilita y abre un camino para los demás (Sennett, 2000). El líder creativo asume un carácter paternalista y asistencial para facilitar el desarrollo personal y creativo de sus empleados:

El líder de empresa del futuro se parece más a una madre o un padre de familia, o un entrenador en un equipo deportivo. Tienes que crear un clima en el que la gente se sienta respetada, sienta que tienes fe en ellos, incluso que los quieres. Tienes que dirigir mediante el amor. Y al hacerlo así, ayudarás a que la gente desarrolle su pleno potencial, se atreva a correr riesgos y emplear su intuición para tomar decisiones. Y pueden hacerlo porque saben que, aunque a veces 
fallen, se les dará una nueva oportunidad. (Goleman et al., 2009, p. 176)

Para Sennett (2000), la ambigüedad del liderazgo, cuando se pierde la explicita función de autoridad para asumir la de posibilitador, puede desorientar a los empleados al dejarlos sin la justificación de alguien que explícitamente desde "arriba" responda. Las palabras emotivas de Goleman interpelan al lector como si éste pudiera ser el líder, aquel paternalista y afectivo guía que promueve el desarrollo (del) personal, cumpliendo la promesa del desarrollo creativo para todos. Los manuales instan a todo tipo de persona, a leerlos y guiarse por ellos. Pero el asunto es que dentro de la pirámide organizacional convencional, el espacio destinado para los cargos directivos es pequeño y está ocupado por pocos. Las relaciones de jerarquía ubican a los individuos en cadenas de mando y dependencia, autorizando a algunos a dirigir y obligando a otros a obedecer (Rose, 1999).

El razonamiento deductivo o silogismo compuesto por las premisas: 1) el gerente es creativo y 2) la creatividad puede ser desarrollada por cualquiera, que conllevarían a la inferencia lógica: 3) cualquier persona al desarrollar su creatividad puede llegar a ser gerente, se torna en falacia en tanto las oportunidades laborales existentes para el ejercicio gerencial suelen estar destinadas a un grupo selecto de personas cuyas proyecciones de formación y ascenso organizacional les anteceden.

Sin embargo, el discurso del desarrollo creativo propone otra solución al anterior silogismo: si solo puede haber algunas "abejas exploradoras" y deben existir muchas "abejas obreras" y por lo tanto no todos podrán llegar a ser gerente de otros, el desarrollo de habilidades creativas sí permitirá el poder llegar a ser al menos gerentes de sí mismos, e incluso desligarse de un entorno organizacional que no esté siendo favorable:

A muchos otros que van a empezar a trabajar no les entusiasma lo más mínimo la idea de sentarse ante un terminal de computador, tener que consultar un manual del empleado y posiblemente perder el empleo si los jefes resuelven reducir el tamaño de la compañía. Están aprendiendo la nueva verdad del empleo: que hoy cada uno es su propio empresario y que las cualidades principales de este nuevo papel son: imaginación, inspiración, ingeniosidad e iniciativa; en una palabra, creatividad (...). Cada vez más personas, en todos los niveles, abandonan la nave del oficio para emprender su propia aventura, a menos que la compañía les dé suficientes oportunidades de ejercer su propia creatividad. (Kao, 1997, p. 11)

Esta "nueva verdad del empleo" revela las condiciones de una realidad laboral donde la demanda es "hacerse responsables de sí mismos", condición que puede llegar a erosionar "cualidades del carácter como la lealtad, el compromiso, los objetivos y la resolución, cualidades que, por naturaleza, son a largo plazo" (Sennett, 2000, p. 29) y que están ligadas a cierta permanencia y fidelidad laboral. Sennett explica que, bajo las nuevas condiciones laborales caracterizadas por la flexibilidad y el cambio a corto plazo, las narraciones espacio-temporales (que acompañaban la vida de los empleados del siglo pasado, por ejemplo), tienden a diluirse en un espacio fragmentario y episódico donde la fuerza de la voluntad y la auto-responsabilidad resultan ser las herramientas de supervivencia de un nuevo tipo de trabajador que opera bajo la consigna de "nada a largo plazo". Los textos analizados contemplan así la posibilidad de que un empleado suficientemente creativo, pueda ser también lo suficientemente independiente como para incluso considerar renunciar a la compañía.

Por otro lado, mientras en los textos se reconoce que los directivos hoy en día cuentan con trabajadores mejor preparados que operan con conocimientos sofisticados y "entienden de negocios, saben qué es la competencia global entre corporaciones, se suscriben a publicaciones de negocios que antes solo se veían en las oficinas de los altos ejecutivos" (Kao, 1997, p. 100), también se reitera que la creatividad se debe promover con cierta mesura, para mantener buenos niveles de motivación intrínseca (Amabile, 2000) y a la vez atajar al empleado (conformista) de convertirse en un líder visionario de sí mismo que quiera reclamar o independizarse. Es perentorio mantener el statu quo de gobierno empresarial, 
mientras se soporta la alta rotación de personal del incierto mundo laboral contemporáneo. El líder "ha dominado el arte de ejercer el poder sin tener que presentarse como responsable" (Sennett, 2000, p. 121), colocando la responsabilidad de las ambigüedades del trabajo sobre los hombros de sus empleados a quienes "facilita" las condiciones para desarrollarse y sobre todo gobernarse.

Y si el autogobierno, como se señalaba en el apartado anterior, está relacionado con las estrategias para modelar las formas de la relación de los individuos consigo mismos -el cómo se experimentan, entienden, juzgan y conducen- podría también señalarse que el discurso sobre el desarrollo de la creatividad empresarial sería una suerte de "tecnología del yo" (Foucault, s. f. citado por Rose, 1998). Las tecnologías del yo pueden ser de tipo epistemológicas (conócete a tí mismo), despóticas (domínate) o de conservación (cuídate), entre otras, y se practican bajo un sentido o régimen de verdad, autoridad y poder real o imaginado (Rose, 1998).

Si se entiende el trabajo como el núcleo de la esfera social, intermedia y a mitad de camino, entre los intereses colectivos y los intereses particulares (Arendt, s. f. citada por Bejar, 1993) este resulta un ámbito propicio para el autogobierno, donde la búsqueda individual del desarrollo de las propias capacidades se organiza y administra socialmente (Bejar, 1993; Rose, 1999), sin ejercer un poder impuesto de manera forzada o violenta, sino con la sutileza que apela a las posibilidades de acción más o menos reflexionadas y calculadas de los individuos (Foucault, 1998).

La noción de autogobierno resolvería salomónicamente la tensión evidenciada en los manuales de desarrollo creativo que separa a directivos de subalternos, justificando que el ejercicio de la creatividad empresarial está destinado para personas capaces de llegar a ser gerentes, si no de otros, al menos de sí mismos. Y en esa medida se ratificaría que toda persona puede ejercer su creatividad y su autorrealización conforme ejerza su autogobierno.

Vale la pena concluir este repertorio remitiéndose a una cita de uno de los manuales que narra una experiencia de éxito empresarial, como ejem- plo inspirador sobre el potencial de la creatividad, incluso no teniendo "nada más" que creatividad:

Raphl Ungermann, quien había trabajado en Intel, era todavía jefe de Zilog, compañía que él mismo fundó, cuando lanzó a First Virtual Corporation en 1993. Como su nombre lo indica, First Visual, empezó sin oficina, sin producto, sin empleados, sin una meta de mercado siquiera. No era más que Ungermann y una idea. La idea de éste era encontrar una metodología para identificar y aprovechar tecnología que estuvieran a punto de arrancar. Ungermann recuerda: "Yo quería hacer algo que sabía que podía hacer: eso era innovar, innovar, innovar e innovar. Quería llevar al mercado en el término de un año, algo que nadie más tuviera, algo que llamara la atención de todos; y después, al año siguiente, volver a hacer lo mismo. Lo verdaderamente interesante era la idea de sacar alguna cosa, ver qué quería de ella el mercado y enseguida desarrollarla rápidamente. Esa es realmente la idea, el desarrollo". (Kao, 1997, p. 55)

Como si las buenas intenciones creativas bastasen por sí solas, esta cita promete develar una formula de acceso al éxito que se apuntala en el puro deseo y voluntad de "querer hacer algo". Sin embargo, la cita misma nos releva el prerrequisito para tal determinación: tener una alta cuota de capital simbólico (Bourdieu, 1993) que permita el acceso y credibilidad en escenarios empresariales. iAdemás de Ungermann, quién o quiénes más estarían en capacidad de lograrlo? Ciertamente no todos, y sin embargo la promesa de una creatividad empresarial de fácil y libre acceso persiste allí, en medio de la tensión entre el líder visionario y el empleado conformista quien, consiguiendo empoderarse de sí mismo, podrá gerenciar creativamente su propio y autodeterminado camino al éxito profesional. Eso sí, sobreponiéndose a la tensión de un mundo laboral cada vez más inestable, sin certeza alguna, sin saber exactamente cómo o con qué herramientas lograrlo, pero impelido puramente por la voluntad de querer "hacer algo nuevo".

Los discursos sobre el desarrollo de la creatividad empresarial podrían entonces contribuir en la configuración de una suerte de ideología del sujeto 
trabajador creativo que asegura la reproducción de las relaciones de producción (Althusser, 2003; Eagleton, 1997), en tanto no solo se sostiene por los intereses de una clase dominante, sino, ante todo, en los intereses, creencias y prácticas de los trabajadores mismos que encuentran en el desarrollo de su creatividad maneras de empoderarse y sobresalir en el demandante mundo laboral. Fairclough (1992) señala que los procesos ideológicos pertenecen tanto a los discursos como a los conjuntos de eventos sociales y por lo tanto son procesos que se dan entre personas. El asunto crítico aquí es que, adicional a que no todos los trabajadores tengan la posibilidad de acceder a las bondades del ejercicio de su creatividad en el ámbito laboral, la tensión paradójica que estos discursos generan implica que el sujeto debe estar dispuesto a una movilización constante, nunca completa, nunca plenamente realizable. La tensión se soporta gracias a la promesa omnipotente de ser capaces de crearse y crear su propio universo de manera libre y autónoma: "La actitud mental positiva es importante: Yo puedo, yo quiero, lo voy a alcanzar" (Schnarch, 2008, p. 47). Porque como señala Fairclough (1992) las ideologías son más eficaces cuando se convierten en sentido común.

\section{Conclusiones}

Las transformaciones sociales de finales del siglo XX e inicios del XXI, en las que por supuesto se considera significativamente el ámbito laboral y que, como se señaló en la introducción, reconfiguran la producción en función del conocimiento, han requerido proponer nuevas tareas a la subjetividad y por tanto transformaciones en la misma. La activación de una conciencia subjetiva a través de la cual el individuo se interpela a sí mismo y modifica las formas de expresión y experimentación de sus ideas y emociones, revela un ambiente de tensión subjetiva (Pedraza, 2010) en la que el individuo supone ser el único responsable de su realidad.

Rose (1999) señala que tanto pensamientos, como sentimientos y acciones, aunque pueden parecer "el propio tejido y la constitución del yo íntimo", desde sus más pequeños detalles están organizados y administrados socialmente y así, el modo como se constituyen reestructuraciones, tareas y demandas a la subjetividad, conforma nuevos saberes sobre los otros seres humanos y el sí mismo, determinando también el modo como se experimenta y aborda el mundo, se genera conocimiento sobre el mismo y se establecen nuevos regímenes de verdad.

En este punto, el análisis discursivo tiene cabida como marco de comprensión de las dinámicas de configuración de nuevos saberes e identidades. Un texto se puede entender como una zona de combate en la que se manifiestan las contiendas discursivas e ideológicas y "los modos en que se utilizan las formas lingüísticas en diversas expresiones y manipulaciones del poder" (Wodak \& Meyer, 2003, p. 31). El análisis de los manuales sobre desarrollo de creatividad empresarial contribuye al estudio de la forma como se configuran, a través de los discursos, nuevos conocimientos psicológicos sobre las identidades que tienen efectos sobre la realidad, en este caso laboral (Stecher, 2010) y en cómo se ejerce el poder sobre los individuos de maneras cada vez más sofisticadas y apuntaladas al desarrollo del yo y sus posibilidades de autorealización.

El cuestionamiento crítico que se quiere plantear aquí es que mientras en los ámbitos laborales las personas se esfuerzan cada vez más por ser creativas y autorrealizadoras, apelando a las posibilidades del autogobierno para hacerse responsables de sí mismos, más se pierde la noción de compromiso a largo plazo y más se carga a los trabajadores de tensiones e incertidumbres sobre su propio ejercicio laboral (Sennett, 2007). Fenómenos como la desregulación y flexibilización laboral o la subcontratación (entre otras condiciones relativamente recientes y propias del neoliberalismo) que hacen cada vez más incierta la vida del trabajador ( $\mathrm{Ne}$ gri, 2004), quedan validados en tanto ofrecen un panorama cuya tensión podría ser propicia para desarrollar la creatividad y autorrealización, las cuales se vuelven indispensables para la supervivencia laboral.

Se trata entonces de una serpiente que se muerde la cola al plantear como único recurso el autodesarrollo individual, sin dejar mayores alternativas 
para el cambio y compromiso social. Un escenario en el que con seguridad los estudios de la psicología social crítica del trabajo tienen mucho que aportar y deconstruir, entendiendo el rol que juegan en el campo laboral las nociones legitimizadas desde la psicología, la cual debe ser también entendida como una tecnología de poder que ha contribuido en la configuración de subjetividades acordes a los principios del entorno macroeconómico imperante (Pulido, 2004).

Si bien esta investigación aborda la pregunta por la configuración de ciertas características de la subjetividad creativa laboral, desde el análisis textual-representacional se entiende también que, como lo expresa Hall (1992 citado por Escobar, Álvarez \& Dagnino, 2001), "la cultura siempre trabaja mediante sus textualidades y al mismo tiempo esa textualidad nunca es suficiente a menos que uno respete el necesario desplazamiento de la cultura" (p. 25). Por lo tanto, este análisis textual se plantea ante todo como una fase teórica desde la cual se puedan proponer otros estudios sobre el tema del desarrollo creativo en contexto, particularmente en la realidad latinoamericana y que contemplen otras dinámicas discursivas a nivel de prácticas, recepción e interacción, que quizás desplacen y resistan el significado mismo y la textualidad de los discursos hegemónicos sobre el deber ser del sujeto trabajador contemporáneo.

\section{Referencias}

Althusser, L. (2003). Ideología y aparatos ideológicos del Estado. En Slavoj Žižek (Comp.), Ideología: un mapa de la cuestión (pp. 115-155). Buenos Aires: Fondo de Cultura Económica.

Amabile, T. (2000). Cómo matar la creatividad. En Creatividad e innovación (pp. 1-31). Bilbao: Deusto. [Amabile, T. (1998). How to kill creativity. Harvard Business Review, 76(5), 76-87].

Bauman, Z. (2005). Amor líquido, acerca de la fragilidad de los vínculos humanos. México/Buenos Aires: Fondo de Cultura Económica.

Bauman, Z. (2006). Modernidad líquida. Buenos Aires: Fondo de Cultura Económica.
Bauman, Z. (2007). Identidad. Buenos Aires: Losada.

Bejar, H. (1993). La cultura del yo. Pasiones colectivas y afectos propios en la teoría social. Madrid: Alianza.

Bejar, H. (2007). Identidades inciertas: Zygmunt Bauman. Barcelona: Herder.

Bourdieu, P. (1993). Espacio social y poder simbólico [Conferencia pronunciada en la Universidad de San Diego en marzo de 1986]. En Cosas dichas (pp. 127-142). Barcelona: Gedisa.

De Bono, E. (1994). El pensamiento creativo: el poder del pensamiento lateral para la creación de nuevas ideas. Barcelona: Paidós.

Deleuze, G. (1998). Post-scriptum sobre las sociedades de control. En Conversaciones 1972- 1990 (J. L. Pardo, Trad.). Barcelona: Pre-Textos.

Eagleton, T. (1997). Ideología. Una introducción. Barcelona: Paidós.

Escobar, A., Álvarez, S. \& Dagnino, E. (2001). Política cultural y cultura política: una nueva mirada sobre los movimientos sociales latinoamericanos. Buenos Aires/Bogotá: Taurus.

Fairclough, N. (1992). Discourse and social change. Londres: Polity Press.

Fairclough, N. (1995). Critical discourse analysis: The critical study of language. Harlow: Longman.

Foucault, M. (1998). El sujeto y el poder. Revista Texto y Contexto, 35, 7-24.

Gardner, H. (1995a). Estructuras de la mente. México: Fondo de Cultura Económica.

Gardner, H. (1995b). Mentes creativas. Una anatomía de la creatividad vista a través de las vidas de Sigmund Freud, Albert Einstein, Pablo Picasso, Igor Stravinsky, T. S. Eliot, Martha Graham, Mahatma Gandhi. Barcelona: Paidós.

Giddens, A. (1996). Modernidad y autoidentidad. En Josetxo Beriain (Comp.), Las consecuencias perversas de la modernidad: modernidad, contingencia y riesgo (pp. 33-71). Barcelona: Anthropos.

Giddens, A. (2000). Modernidad e identidad del yo: el yo y la sociedad en la época contemporánea. Barcelona: Ediciones Península.

Goleman, D., Kaufman, P. \& Ray, M. (2009). El espiritu creativo. Barcelona: Ediciones Zeta.

Kao, J. (1997). Jamming: el arte y la disciplina de la creatividad en los negocios. Bogotá: Editorial Norma. 
Landau, E. (1987). El vivir creativo. Teoría y práctica de la creatividad. Barcelona: Herder.

Martin, R. (2008). Ideas opuestas, soluciones creativas. Bogotá: Norma.

Maslow, A. (2001). La personalidad creadora. Barcelona: Kairós.

Naranjo, C. (2010). Dimensiones del conocimiento en la organización. En E. Martínez Jáuregui (Comp.), Creatividad e innovación (pp. 44-65). Manizales: Universidad Autónoma de Manizales.

Negri, A. (2004). A propósito de la ontología social: trabajo material, inmaterial y biopolítica. En Guías. Cinco lecciones en torno a imperio. Barcelona: Paidós Estado y Sociedad.

Pedraza, Z. (2010). Exposición, ilustración y experiencia del mundo emocional. C. E. Acosta \& C. Alzate (Comps.), Relatos autobiográficos y otras formas del yo (pp. 49-69). Bogotá: Siglos del Hombre/Universidad de los Andes.

Potter, J. \& Wetherell, M. (1998). El análisis del discurso y la identificación de repertorios interpretativos. En A. Gordo \& J. Linaza (Comps.), Psicologías, discursos y poder (pp. 63-78). Madrid: Visor.

Pulido, C. (2004). En búsqueda de una psicología crítica en los ámbitos laborales. Universitas Psychologica, 3(2), 213-222.
Pulido, C. (2007). Produciendo trabajadores modernos: conocimiento psicológico y el mundo del trabajo en el sur. Universitas Psychológica, 6(1), 27-37.

Rose, N. (1998). Inventing our selves: Psychology, power, and personhood. Cambridge, UK/New York: Cambridge University Press.

Rose, N. (1999). Governing the soul: The shaping of the private self. London/New York: Free Association Books.

Schnarch, A. (2008). Creatividad aplicada. Bogotá: Ecoe.

Sennett, R. (2000). La corrosión del carácter. Las consecuencias personales del trabajo en el nuevo capitalismo. Barcelona: Anagrama.

Sennett, R. (2007). La cultura del nuevo capitalismo. Barcelona: Anagrama.

Stecher, A. (2010). El análisis crítico del discurso como herramienta de investigación psicosocial del mundo del trabajo. Discusiones desde América Latina. Universitas Psychologica, 9(1), 93-107.

Walkerdine, V. (2006). Workers in the new economy: Transformation as border crossing. Ethos, 34(1), 10-41. Winnicott, D. (2008). Realidad y juego. Barcelona: Gedisa.

Wodak, R. \& Meyer, M. (2003). Métodos de análisis crítico del discurso. Barcelona: Gedisa. 